\title{
ARTIGOS
}

\section{ENCONTROS MARCADOS:}

\author{
SOBRE NARRATIVAS, POLÍTICAS DE ALIANÇA E SAÚDE \\ MENTAL LGBTI+
}

\author{
Allan Dayvidson de Azevedo Menezes ${ }^{1}$ \\ Viviane Suzano Martinhão ${ }^{2}$
}

Resumo: Neste artigo apresentamos o tema da saúde mental da população LGBTI+ para além das formalidades estatais. Abordamos as narrativas de histórias de vida estabelecidas nos encontros entre essas pessoas, viabilizados por coletivos LGBTI+ desde grupos de ativistas, de amigos, ou mesmo situações sociais como festas e encontros inesperados. Perguntamo-nos como esses espaços-momentos podem viabilizar a circulação das narrativas LGBTI+, a elaboração de memórias, e a própria constituição subjetiva dos sujeitos através do compartilhamento de experiências singulares e que, ao mesmo tempo, carregam ou performam rastros de comum. Estendemos a reflexão para como isso pode contribuir na tecitura de uma rede de cuidado mais ampla, que ativamente promova estratégias, alianças e condições mais vivíveis, constituindo-se como formas de acolhimento, atenção, cuidado e proteção que promovem e fortalecem a saúde mental. Reconhecemos a importância de seguirmos na luta pela garantia de políticas, mas apostamos que não basta apenas buscarmos a garantia de saúde através do poder público, sendo importante pensar formas outras de proporcionar espaços de encontros que criem, ou ajudem a criar, as condições de (sobre)vivência menos vulnerabilizadas pelas opressões cotidianas, bem como estratégias de enfrentamento das realidades opressivas. Diante da atual realidade política precisamos (re)considerar nossas lutas e práticas, buscando meios de fazer com que nossas vidas sejam mais vivíveis, compreendendo o cuidado mútuo para a abertura às multiplicidades das vidas e narrativas que perseveram. Atentamos para a construção de redes interseccionais de alianças, entendendo que diversos marcadores de diferença são convocados nessa luta pelo direito à liberdade de sermos plurais.

Palavras-chave: Saúde Mental LGBTI+; Memória LGBTI+; Narrativas; Políticas de Aliança; Redes de cuidado.

\section{Introdução}

\footnotetext{
1 Bacharel em Psicologia pelas Faculdades Integradas Maria Thereza; Mestre em Psicologia pela Universidade Federal Fluminense; Doutorando em Psicologia pela Universidade Federal Fluminense, bolsista CAPES. E-mail: allandayvidson@gmail.com

2 Psicóloga e Bacharel em Psicologia pela Universidade Estadual Paulista "Julio de Mesquita Filho", Mestre em Psicologia Social pela Universidade do Estado do Rio de Janeiro; Doutoranda em Psicologia pela Universidade Federal Fluminense, bolsista CAPES. E-mail: vivis.martinhao@gmail.com
}

Vol. 02, N. 01, Jan. - Mar., $2019 \cdot$ www.revistas.unilab.edu.br/index.php/rebeh 
Marcamos um encontro, eu e você. No momento em que começa a ler este artigo, tomo como marcado este evento. Digo "marcado" não porque combinamos previamente de nos ver, mas porque ele é constitutivamente repleto de marcas. O lugar enunciativo "eu" que aqui comparece diante de ti neste ponto de encontro não diz respeito meramente a uma amálgama ou articulação de individualidades de dois pesquisadores representadas num texto. Ficam apenas rastros destes autores que aqui escrevem, junto aos rastros de diversas categorias históricas, de parcerias humanas e não-humanas e (des)encontros, que oportunamente se constituem em texto e são rasurados continuamente por aquelas/es que leem. Viemos (nós e você) a este encontro talvez por razões distintas, mas se comparecemos é porque há algo da persistência de nossas vidas que só é possível no ato de encontrar. Essa persistência da vida, em lutar por vivê-la é uma constante para a população $\mathrm{LGBTI}^{3}{ }^{3}$ que diariamente enfrenta intolerâncias, preconceitos e discriminações por ser considerada como um grupo anormal em relação aos padrões de sexo e gênero determinados e reproduzidos pelo poder hegemônico vigente. Para essas pessoas a oportunidade do encontro pode ter desdobramentos positivamente significativos e fortalecedores, diante de uma vivência cotidiana de opressões e violências sofridas na/pela nossa sociedade.

Certamente nem todo encontro pode se estabelecer como positivo, mas o que tentaremos colocar em evidência aqui são alguns aspectos importantes para que os encontros promovam e impulsionem experiências potentes e fortalecedoras, e não (re)produzam experiências tóxicas, intolerantes ou mesmo violentas para aqueles que o componham. Nosso corpo teórico contará com autoras e autores que a princípio podem não compor com frequência nos debates de saúde mental. Essa escolha é uma aposta. Primeiro, por essas autoras/es comparecerem como nossas bases teóricas enquanto pesquisadores. Segundo, para esticarmos suas assertivas de modo a contribuir com as discussões sobre saúde mental para pessoas LGBTI+.

Nossas reflexões, por sua vez, percorrerão tanto pelos encontros cotidianos, casuais, quanto por aqueles com propósitos mais ou menos estabelecidos, aqueles promovidos com foco em atividades e encontros ativistas e demais eventos voltados para

\footnotetext{
${ }^{3} \mathrm{~A}$ sigla LGBTI+ tem sido usada mais recentemente por algumas pessoas do movimento social e em algumas escritas acadêmicas. Optamos pelo seu uso por considerá-la abrangente quanto à diversidade e pluralidade das inúmeras vidas que ela pretende representar.
}

Vol. 02, N. 01, Jan. - Mar., 2019 - www.revistas.unilab.edu.br/index.php/rebeh 
pessoas LGBTI+, podendo fazer deles espaços potentes (e para alguns o único espaço) em que se apresentam possibilidades de amparo, (re)afirmação de alianças, elaboração de estratégias, promoção de (in)formações e, inclusive, de alegria, bem-estar e alívio para alguns dos sofrimentos recorrentes. Sendo assim, esses espaços podem ser oportunidades que contribuam/colaborem, em diversos níveis e maneiras, com a abertura e constituição de formas de acolhimento, proteção e promoção de suas saúdes mentais vulnerabilizadas por essa realidade.

Como nós LGBTI+ vimos persistindo vivas e vivos? Ao longo de 40 anos de atuação e luta do movimento que hoje conhecemos como $\mathrm{LGBT}^{4}$, a união entre pessoas marginalizadas tem construído força e sentido para o enfrentamento das opressões e da busca de condições mais vivíveis. Estar em coletivo, em muitos momentos, se estabelece não apenas como um caminho para se encontrar com pessoas que compartilhavam vivências e exclusões semelhantes, mas principalmente o meio e o fim da promoção de bem-estar, da promoção de espaços em comum, da promoção de algum tipo de segurança de que nessa luta não estamos sozinhas, tornando esses também termos das lutas e resistências. Muitas pessoas LGBTI+ relatam a importância desses encontros, seja através de grupos na internet ou pessoalmente, realizados por instituições como ONGs, ou ainda pela organização de alguns coletivos como formas de se manterem vivas e resistentes.

A realidade vivenciada no Brasil para essa população sempre foi de hostilidade, de opressão e discriminação. Nessas quatro décadas de luta, muitos foram os enfrentamentos que culminaram em conquistas quanto ao acesso e garantia de direitos e cidadania para esse grupo. Mas essa luta sempre foi penosa, e algumas conquistas foram incipientes e/ou insuficientes, ou mesmo quando estas se mostravam como um marco na história dos direitos humanos para esse grupo, logo elas se perdiam devido a "novos" entraves estruturais e problemas em suas execuções, quando não foram alvo de

\footnotetext{
${ }^{4}$ A sigla LGBT foi escolhida e decidida como representativa desse grupo a partir de diversos momentos de seu desenvolvimento, enquanto movimento social e vidas em resistência. Na década de 1970 o movimento era denominado Movimento Homossexual Brasileiro (MHB), mudando depois para movimento GLBT, a partir da Associação da Parada do Orgulho GLBT de São Paulo. Foi em 2008, na I Conferência Nacional GLBT, realizada no âmbito das ações previstas no Programa Brasil sem Homofobia, que a reivindicação de ativistas lésbicas levou à mudança do termo. Embora ainda haja algumas variações do termo, a sigla LGBT vem sendo a mais recorrente, nos últimos 10 anos, para representar o movimento social em questão (MARTINHÃO, 2017).
}

Vol. 02, N. 01, Jan. - Mar., 2019 - www.revistas.unilab.edu.br/index.php/rebeh 
impedimentos declarados na realização de políticas já estabelecidas ou em fase de implementação ${ }^{5}$. O marco dos direitos da população LGBTI+, o Programa Brasil Sem Homofobia, implementado em 2004 no governo do presidente em exercício Luís Inácio Lula da Silva, foi uma conquista muito aplaudida, mas que logo foi sendo atravancada, engavetada e aniquilada pelos governos seguintes. Na nossa atual conjuntura política o presidente em exercício, que tomou posse para início de seu mandato nesses primeiros dias de janeiro de 2019, já manifestou várias vezes seu repúdio à população LGBTI+, e inclusive já anunciou, no primeiro dia de sua posse, medida provisória que pretende excluir essa população das políticas e diretrizes voltadas à promoção de direitos humanos (DIÁRIO DE PERNAMBUCO, 2019).

$\mathrm{Na}$ luta da resistência para a existência são os coletivos, os grupos ativistas e demais encontros entre essa população que podem colaborar para a garantia de fortalecimento e proteção da saúde mental dessas pessoas. Diante de uma iminente possibilidade de sermos terra arrasada nas políticas excludentes que já se mostram, precisamos (re)considerar nossas lutas e práticas, (re)pensar e (re)conhecer formas de nos mantermos vivas.

No que tange o tema de saúde mental para a população LGBTI+, essa ainda é uma problemática de difícil resolução. Embora haja algumas diretrizes governamentais que propõem a garantia de saúde para esse grupo, a saúde mental ainda aparece nos debates de modo escasso e de pouco alcance para essas pessoas. Ainda que já tenha sido abordado sobre a vulnerabilidade e riscos que muitas dessas pessoas enfrentam cotidianamente e como sua condição mental fica gravemente fragilizada e ameaçada levando inclusive a altos índices de depressão, ansiedade e suicídio ${ }^{6}$ - e os processos de cuidado, atenção e assistência comparecerem nas nossas discussões, ainda assim não têm sido suficientes.

\footnotetext{
${ }^{5}$ Um exemplo que consideramos emblemático foi o caso do kit anti-homofobia, preconceituosamente apelidado de "kit gay", como uma política que foi duramente barrada e acabou representando a derrocada das políticas LGBT conquistadas a partir do Programa Brasil sem Homofobia. Para saber mais ver Soares (2015) e Amélia (2018).

${ }^{6}$ Para maiores informações sobre o tema sugerimos a consulta dos trabalhos de Teixera Filho e Rondini (2012) e de Peres, Soares e Dias (2018).
}

Vol. 02, N. 01, Jan. - Mar., 2019 - www.revistas.unilab.edu.br/index.php/rebeh 
Insistamos na pergunta: como vimos persistindo vivos e vivas? Quais alianças e estratégias de cuidado mútuo nós vimos forjando até aqui? É claro que precisamos estender a percepção sobre quais vidas conseguem caber nesse "nós". Acompanhamos Haraway (2009) e Reagon (2000) na indagação sobre esse mito político potente que chamamos de "nós", apontando para a não autoevidência das categorias e suas necessárias reformulações na medida em que nos encontramos umas com as outras. Mais que isso, precisamos compreender os atravessamentos interseccionais (como raça, etnia, classe social, capacidade, geração, dentre outros) que compõem nossas identidades sexuais e de gênero. Cabe lembrar que o medo e insegurança em sermos pessoas LGBTI+ no Brasil sempre se acentua quando nos deparamos com os altos índices de assassinato dessa população, e nosso país segue calamitosamente no rank internacional dessas estatísticas (REIS, 2018). Tal receio é porque no limite todas nós estamos em risco. Todavia, ao mesmo tempo, compreendemos que a exposição a riscos também é desigual na medida em que uma pessoa LGBTI+ esteja marcada por outra(s) identidade(s) minoritária(s) também em risco; as condições de viabilidade e preservação dessas vidas são relativamente mais estreitas, ainda que assumamos a impossibilidade de estabelecer, quantitativa ou qualitativamente, uma escala de risco definitiva para esse complexo cenário. Não se trata de definir quem sofre ou se arrisca mais, mas de reconhecer que a distribuição demográfica desigual de precariedade também comparece no interior das categorias.

Outro fator significativo quando falamos de saúde mental é que seu âmbito acaba muitas vezes restringindo-se ao tema da promulgação de políticas públicas de saúde que garantam o acesso e atendimento condizente às demandas das pessoas LGBTI+ nos serviços de saúde. No que tange à luta antimanicomial no Brasil, os diversos debates, discussões e avanços promovidos por essa frente parecem ainda não ter alcançado devidamente esse grupo e/ou a temática de gênero e sexualidade. Sabemos o quanto o direito à saúde pública é fundamental e precisa se estabelecer formalmente, mas, para as realidades vivenciadas pela população LGBTI+ ainda encontram muita opressão e discriminação provocadas incisivamente pela negligência, descaso e omissão por parte dos estados e governos.

Vol. 02, N. 01, Jan. - Mar., 2019 - www.revistas.unilab.edu.br/index.php/rebeh 
Ainda nos deparamos com outra problemática intrínseca: mesmo que algumas políticas sejam sancionadas e implementadas, os serviços de saúde, muitas vezes, se encontram não só deteriorados e desinvestidos pelos estados e governos, como a própria forma de implementação das políticas é precária, pois quando postas em ação muitas vezes é difícil adequá-las para atenderem às diversas necessidades desse grupo, e o resultado final das ações acabam ficando muito aquém dessas demandas. A população em questão vê-se, assim, frequentemente desassistida pelas políticas e serviços. Quando o estado e governos se omitem de seus compromissos e responsabilidades com populações em risco, ainda mais quando o fazem deliberadamente ao não proverem proteção e segurança diante dos casos de violência e horror contra a população LGBTI+, eles se tornam responsáveis também por essas opressões, pelas violências e pelas mortes direcionadas a esse grupo, promovendo uma homofobia de estado (MARTINHÃO, 2017), que se direciona a todas as pessoas LGBTI+.

Apropriarmo-nos dessa perspectiva em que compreendemos as populações LGBTI+ como vulnerabilizadas por políticas que as desconsideram ou mesmo pela ausência de políticas e, sobretudo, da responsabilização do Estado em relação a isso, certamente, tem orientado nossas militâncias por ações macropolíticas importantes muito vinculadas às lutas por direitos. Mais do que considerar a precariedade desses processos, levantamos a questão de que a concepção de saúde e bem-estar mental vão muito além dessa dimensão. Ou melhor, defendemos que é preciso investir também num campo reflexivo que considere aquilo que se estabelece nos encontros locais e que possivelmente não constará na maioria dos contratos e projetos de lei, mas que se constrói e se firma noutros termos talvez menos simples, mas igualmente éticos. Podemos considerar, por exemplo, que promoção de saúde mental também está no âmbito das práticas sociais, relacionando-se com a promoção de formas de vivência pelas diferenças, de respeito às diversidades, de diminuição de padrões sociais de preconceito e discriminação, e afirmar o papel que políticas educacionais poderiam assumir nesse sentido. Mas em um cenário político em que se torna cada vez mais difícil e ardilosa qualquer negociação com as instituições políticas nesse sentido e vemos mais constantemente um violento sufocamento de canais de reivindicações, o que fazemos? É claro que precisamos continuar pressionando o estado por nosso reconhecimento, de

Vol. 02, N. 01, Jan. - Mar., 2019 - www.revistas.unilab.edu.br/index.php/rebeh 
modo algum devemos abandonar essa frente. No entanto, precisamos cavar mais trincheiras rumo a mais frentes, traçar mais estratégias e caminhos, capilarizar a luta por condições dignas de serem vividas e, sobretudo, cuidarmos umas das outras nesse processo. Do contrário, nos reduziremos à colisão de forças e ao denominador comum da violência no campo de batalha, já bastante minado por aqueles determinados a literalmente eliminar nossas existências.

Portanto, nosso foco aqui está nas produções narrativas que são forjadas localmente no coletivo em comum, mas que também levam consigo rastros de toda uma categoria histórica. As narrativas são necessariamente modos discursivos (marcados pelas singularidades) de se posicionar em relação a um legado e de transmissão das experiências (BENJAMIN, 1987). Elas remontam não só as histórias pessoais de quem narra, mas apontam que a própria pessoalidade da narrativa se constitui em contingências históricas. Sendo assim, o "pessoal" não corresponde à expressão de uma individualidade, mas singularidades de uma subjetividade altamente referida a rastros históricos.

Para nós, a narrativa dilui a centralidade de quem partilha uma história, quando toma a palavra. [...] Para nós, a narrativa de si [...] se remete ao compartilhamento de fragmentos das instituições que regulam e validam atos e construções de identidades sexuais, mas também a ausência da facticidade de um eu anterior aos procedimentos de enunciação, ao choque com o poder, as políticas de subjetivação que forjam os gêneros e as identidades sexuais. (FERREIRA, 2016, p. 109)

Quem partilha uma história perde a centralidade, mas não necessariamente deixa de ser amparada/o pela própria história. Ao contrário, ela passa a ser compartilhada por diversas vidas também marcadas por rastros históricos comuns, amplia sua capacidade conectiva com essas vidas em direção a condições mais vivíveis. Deste modo, buscamos nas narrativas um meio de ampliar nosso pensamento quando nos referimos à saúde mental, não para reconceituar esta última, mas para rasurar o termo de modo a podermos pensar em outros canais de cuidados de saúde mental, ampliando nossas possibilidades de tecer redes de cuidado. Tendo isso por premissa, precisamos construir redes e debates sobre saúde que não se detenham apenas à luta por políticas públicas. Com considerável empenho, precisamos investir também em ações e reflexões micropolíticas, em interações cotidianas sem as quais muitos de nós certamente não estaríamos aqui, nos encontros. Não devemos abandonar a luta por direitos e políticas que o estado deve nos

Vol. 02, N. 01, Jan. - Mar., 2019 - www.revistas.unilab.edu.br/index.php/rebeh 
garantir, mas quando o estado se coloca violentamente em oposição à promoção de saúde de nós LGBTI+, não só construindo obstáculos e nos abandonando à própria sorte, mas efetivamente incitando a violência contra nossos corpos, precisamos de mais alianças para além das formalidades estatais.

Todavia, não pretendemos esgotar ou solucionar essas questões, mas sim levantálas, suscitá-las, trazê-las aos sentidos daquelas/es que são afetados por esse tema (DELEUZE; PARNET, 1998). Pensar em promoção de saúde mental é mais do que construir estratégias para oferta de políticas e serviços públicos de saúde mental, mas também pensar em formas de proporcionar espaços de encontros que fortaleçam as condições de (sobre)vivência desse grupo através de uma possível reparação e melhoria de suas saúdes mentais fragilizadas pelas opressões cotidianas. Proporcionar esses espaços-momentos também nos demanda refletir sobre o que está em jogo na constituição dessa suposta espacialidade e momentaneidade nas quais um encontro com potencial de cuidado possa se dar. Certamente, as situações são moldadas pelo complexo conjunto de contingências que viabilizam com mais facilidade certas interações em detrimento de outras. Por exemplo, um beijo entre duas pessoas do mesmo gênero tende a ser menos policiado numa boate voltada para a população LGBTI+ do que numa rua da cidade no meio do dia, logo, provavelmente esse tipo de interação tenderá a ser menos comum neste último cenário. Isso não impede totalmente que em determinado momento tenhamos nossos beijos policiados na boate, e nem que muitas de nós resistamos exercendo nosso direito a expressar nossos afetos em público como quaisquer outros sujeitos, cuja sexualidade aparentemente em conformidade com as normas dominantes, também o fazem.

Sendo assim, os encontros não são definitivamente determinados pelas infraestruturas física, virtual e simbólica, logo, não faz sentido uma busca por uma forma ideal, tampouco uma receita de como forjar essas possibilidades, embora precisemos acordar algumas condições mínimas. Os encontros se dão porque há subjetividades que circulam por ali (seja lá onde for esse "ali") e com elas um quantum de imprevisibilidade, singularidade e potencial criativo também. Então, o que tornaria um recorte no tempo-espaço uma oportunidade de relações de cuidado mútuo, de elaboração de memórias, de valorização da saúde mental dos envolvidos?

Vol. 02, N. 01, Jan. - Mar., $2019 \cdot$ www.revistas.unilab.edu.br/index.php/rebeh 
As identidades muitas vezes viabilizam "pontos de encontro", e não raro se estabelecem como um comum possível entre diversos sujeitos marcados por elas, sejam por meio de rastros das experiências alegres, das traumáticas, de questões em comum, etc. Ainda assim haverá sujeitos a diferentes graus de distância em relação a esses pontos de encontro, nem todos terão as mesmas condições de chegar. Pode ser por questões como acesso a serviços públicos básicos como transporte e educação; talvez pela ausência de infraestrutura adequada a pessoas com deficiência; por não se sentir devidamente reconhecida sendo a única pessoa LGBTI+ negra, gorda e com deficiência presente numa festa; por não se sentir ouvida pelos outros dentro de um espaço acadêmico; por não se sentir bem-vinda nos aplicativos de relacionamento por ser considerada bicha afeminada. Os cenários possíveis são inúmeros, podemos ficar aqui infinitamente listando-os. Não há plataforma a priori que garanta sequer que haja encontros, quanto mais que estes possam vir a ser benéficos para os envolvidos, mas o que nos interessa neste momento são outras histórias para os encontros, aquelas em que eles se estabeleçam como espaços-momentos que contribuem para a circulação das narrativas plurais e singulares, permitindo-nos sentir que não estamos completamente sozinhos em nossas dores e alegrias, permitindo alguma companhia na (re)elaboração de nossa própria história.

Esse debate então se faz importante para cultivar os espaços-momentos em que é possível contribuir para promoção de saúde das populações LGBTI+, ao mesmo tempo em que nos permite alguma autocrítica a respeito de como esses espaços-momentos vêm se montando ou sendo desmontados, quais categorias de fato eles têm favorecido, quais intersecções podem não ter sido consideradas. Por isso empreendemos reflexões neste estudo para compreender como essas oportunidades de estarmos juntas e diante umas das outras, em diversos níveis e maneiras, inferem diretamente na produção de saúde mental das populações LGBTI+. Em especial, esses espaços-momentos de trocas entre pessoas LGBTI+ não são pensados a partir da ordem da técnica, do especialismo ou do terapêutico (embora possam proporcionar algum efeito nesse sentido), mas sim pautados sob uma ótica de transição de legado, de certo trabalho de elaboração da memória e principalmente da elaboração de experiências possivelmente traumáticas, a partir dos relatos de experiência das histórias de vida que acontecem nos encontros. Assim visamos

Vol. 02, N. 01, Jan. - Mar., 2019 - www.revistas.unilab.edu.br/index.php/rebeh 
abordar e exaltar a promoção desses encontros, mas, sobretudo, pensar criticamente as condições nas quais eles se tornam possíveis. A hipótese que aqui lhe propomos é a de que essas oportunidades de estarmos juntas/os e diante de umas das outras têm potencial de promoção de saúde.

\section{Pontos de Encontro}

Compreendemos junto à filósofa Judith Butler (2018) que coabitamos um mundo e compomos uma sociedade ainda marcada por regimes disciplinadores e reguladores que operam uma distribuição demográfica da precariedade extremamente desigual, no interesse da primazia de certas categorias históricas sobre outras. Umas das principais estratégias de dominação (e muitas vezes de aniquilamento) das categorias indesejáveis é a restrição e o sufocamento de canais de transmissibilidade das experiências que não coincidem satisfatoriamente aos padrões normativos dominantes. Vemos isso, por exemplo, quando pleiteamos por canais para nossas narrativas em espaços públicos e se estabelecem rapidamente obstáculos, censuras e teorias de conspiração infundadas de modo a tentar mostrar, da maneira mais sensacionalista possível, que isso seria danoso à sociedade, traria destruição à espécie humana, ou algo do tipo. Isso se dá justamente porque se reconhece, de modo consciente ou não, a capacidade das narrativas de abalarem o status quo, os mecanismos de dominação e controle social. Por outro lado, nesse cenário, se intensifica a precariedade das vidas minoritárias ${ }^{7}$ que pleiteiam por condições mais igualitárias de persistirem vivas. Se concordarmos com Butler (2015) quando esta afirma que uma vida não narrável é uma vida invivível podemos intuir também que as condições de promoção de saúde dessa vida são sistematicamente deterioradas por diversos mecanismos de silenciamento e exclusão. Nós LGBTI+ somos, assim, constantemente tolhidas das possibilidades de relatarmos nossas experiências, a não ser sob o julgo explícito ou implícito do interrogatório e da confissão, como nos aponta o filósofo Michel Foucault (2015), tendo na exposição e revelação da

\footnotetext{
${ }^{7}$ Embora consideremos que o grupo em questão não seja propriamente uma minoria numérica da população brasileira, esse termo faz referência à ideia de "movimentos de minorias" cujas "lutas se voltam preferencialmente para a melhoria das condições de existência de segmentos específicos da sociedade, mais do que às populações como um todo. Além disso, a 'minoridade' desses grupos seria um reflexo da discriminação sistemática que sofrem, o que lhes veda o acesso a um poder político-econômico mais compatível com seu número" (MACRAE, 1990, p. 25).
}

Vol. 02, N. 01, Jan. - Mar., 2019 - www.revistas.unilab.edu.br/index.php/rebeh 
privacidade, trazida para o âmbito público, uma forma de controle dos desejos e dos corpos pelos poderes hegemônicos vigentes. Ao forjar um "quem sou eu", ou melhor, forjar uma interioridade seriada que corresponda a uma demanda de verdade, viabilizase uma captura mais especializada por mecanismos disciplinares e de controle, assim como os "armários" que nos constituem e dos quais, Sedgwick (2007) argumenta, nunca saímos definitivamente, pois permanecem atuantes e presentes nas nossas relações e determinações sociais. Nas palavras da autora:

Cada encontro com uma nova turma de estudantes, para não falar de um novo chefe, assistente social, gerente de banco, senhorio, médico, constrói novos armários cujas leis características de ótica e física exigem, pelo menos por parte de pessoas gays, novos levantamentos, novos cálculos, novos esquemas de demandas de sigilo ou exposição. (Sedgwick, 2007, p. 22)

Mesmo diante disso, também construímos modos de resistir em relação a essas dominações. No entanto, somos constitutivamente seres interdependentes e essa dimensão é inalienável da tarefa de persistir vivendo. Tendo isso por premissa, a vida digna de ser vivida para Butler $(2015 ; 2016 a ; 2016 b$; 2018) só pode ser entendida se compreendemos a noção de precariedade. A autora nos sugere que as definições do que é ou pode contar como vida não dizem respeito simplesmente a um percurso no espaçotempo que cumpre apenas requisitos puramente biológicos e/ou humanistas de um ciclo natural inquestionável, mas, acima de tudo, um exercício de persistência. Viver é arriscado, demanda trabalho e coligações com outros seres vivos e não-vivos. É, em suma, fazer algo para permanecer vivo. Neste sentido, uma vida só prossegue junto a outras vidas e essa precariedade é ontológica de nossa subjetividade. Melhor dizendo, o “eu” só se estabelece como lugar enunciativo a partir do qual o sujeito trilha seu caminho pelos discursos porque há um "tu” efetiva e/ou simbolicamente que interpela e demanda enunciação. O "eu” já surge cindido, precário, opaco, incapaz de remontar todas as condições que lhe deram uma suposta origem e altamente referenciado pelas conexões disponíveis. Logo, qualquer relato que alguém pode fizer de si está minimamente condicionado por aqueles e aquelas a quem ela/ele se dirige, assim como todas as contingências a partir das quais uma enunciação se levanta. Portanto, a precariedade não se resume apenas ao risco de ausência ou perturbação de sinais vitais de um corpo, mas a condições simbólicas e políticas de um corpo ser reconhecível como vida e por meio das quais ele consegue recursos para persistir. O reconhecimento

Vol. 02, N. 01, Jan. - Mar., 2019 - www.revistas.unilab.edu.br/index.php/rebeh 
aparece assim não apenas como apreensão prévia de uma identidade ou um conhecimento sobre quem é essa vida, embora requeira alguma inteligibilidade. Reconhecer a viabilidade de uma vida passa por apreendê-la como digna de lamento, caso seja perdida. Isso vale tanto para uma vida humana, quanto de outro animal, ou mesmo de uma planta ou microrganismo.

Quando uma vida é apreendida como digna de luto se estabelecem ações e conexões para compor com sua persistência. O oposto também é verdadeiro: na medida em que uma vida se encontra impedida de um reconhecimento devido, ela vê-se desassistida em diversas dimensões em seu exercício de persistir, ou seja, sua precariedade é maximizada. No caso das narrativas LGBTI+, a escassez de espaços e canais amplos de transmissibilidade das experiências e modos de existir, dificulta as possibilidades de suas necessidades serem devidamente reconhecidas e acolhidas pela sociedade. Nos termos aqui adotados, a dignidade das diversas vidas que essa sigla tenta reconhecer se encontram em diferentes proximidades dos limites do que é reconhecível como vida vivível. Em outras palavras, como somos tolhidas de diversos recursos discursivos e espaços para elaboração de nossas histórias, encontramos dificuldades para que a sociedade reconheça as complexidades e especificidades de nossas existências, muitas vezes sendo encobertas ou resumidas a narrativas superficiais, imprecisas e até injustas que visam nossa desumanização e subconsequente destituição da dignidade de nossas vidas.

Diante da precariedade, é no coletivo que podemos encontrar outras formas de reconhecimento, a partir dos pares, e podendo assim encontrar outros caminhos que permitam certa diminuição dessa precariedade. O filósofo Benedictus de Spinoza (2009) nos mostrou a importância dos encontros produzidos nos coletivos como meio de aumentar as potências das pessoas que o compõe. Essas potências viriam a agregar positivamente em cada um, podendo se transformar em resistências às dificuldades vivenciadas e compartilhadas no cotidiano. Para ele a potência é ilimitada, bastando ser acionada, e é por ela que se sobrevive, embora todo ser esteja sujeito a potências maiores do que ele que possam fazê-lo sucumbir. Ele fez um elogio ao coletivo, que representa também a multiplicidade que compõe todo o universo. Mas como acioná-lo? Corpos juntos não constituem exatamente um coletivo, mas quando corpos em junção podem se

Vol. 02, N. 01, Jan. - Mar., 2019 - www.revistas.unilab.edu.br/index.php/rebeh 
tornar mais fortes e pensarem melhor tem-se aí a constituição de um coletivo, de modo que são os nossos afetos - que não são um sentimento a priori, mas sim um princípio de causalidade que não é binário, não é de causa e efeito, mas é variação da experiência e da experimentação -, influenciados pelos semelhantes, que colaboram para sua junção. Embora para ele a semelhança não seja bem positiva, pois é imaginária, ainda assim a semelhança interfere na construção dos coletivos, mesmo que neles as pessoas possam conflitar, pois através do plano comum estabelecido, a partir das semelhanças, que um coletivo pode se constituir. De certo modo, a semelhança por si só não garante um comum pré-determinado, embora não seja possível estabelecê-lo sem esse tipo de comparação. Talvez aquilo que viabilize que um coletivo persista seja a constituição desse comum, mas que precisa se constituir no próprio exercício do encontrar, e a semelhança presumida aparece muitas vezes como rastro oportuno ou pretexto para essa comunhão.

A ativista Bernice Reagon (2000) defendeu em seu discurso, em um festival de música feminista, que numa reunião de mulheres, a cada nova mulher que entra pela porta, a categoria "mulher" precisa se reformular. Essa talvez seja a mesma radicalidade que devamos sustentar como pessoas LGBTI+. Não nos reconhecemos sob uma sigla com tantas reformulações em suas letras e símbolos há mais de quatro décadas à toa, pois elas correspondem a um empenho em constituir um comum entre sujeitos que vivem seus gêneros e sexualidades de modos muito diferentes entre si. Por isso a importância de não apaziguarmos esse comum como dado, nem fazer o oposto e subestimar sua consistência. Se para Butler (2018) esse comum diz respeito a nossa exposição injusta à precariedade, Reagon (2000) complementa que não devemos ter essa comunalidade por autoevidente e tampouco estática.

Por outro lado, quando nos reunimos, nos transformamos mutuamente, não necessariamente pelo que se assemelha em nós, mas pelas diferenças. Pode parecer confuso, porque de fato há um paradoxo aqui. Se as pessoas LGBTI+ podem se encontrar e reconhecer alguma semelhança em termos de marcas e experiências, o encontro em si só é possível porque há diferenças, do contrário seria difícil reconhecermos umas às outras, veríamos apenas a nós mesmas e nenhuma transformação seria possível. Por outro lado, estar juntas, estar diante de alguém que se

Vol. 02, N. 01, Jan. - Mar., 2019 - www.revistas.unilab.edu.br/index.php/rebeh 
assemelha a você em certo sentido, mas que também é um outro, lhe interpela e rasura a você mesma/o. A pergunta 'Quem sou eu?' vem necessariamente acompanhada de 'Quem és tu?' (BUTLER, 2015), pois a primeira questão só se estabelece diante de uma demanda por responder a um outro.

Nesse potencial de transformação reside outro potencial: o de produção de saúde mental. Os encontros que permitem a possibilidade de nós LGBTI+ elaborarmos nossas experiências, nossas memórias, nossos traumas, que permitem que revisitemos lembranças alegres ou tristes, que circulemos pelos cotidianos umas das outras, esses encontros nos permitem viver, nos auxiliam a cuidar coletivamente de nossa saúde mental.

Desta forma, nosso argumento se distancia especialmente de Reagon (2000). Ela é categórica em sua fala ao separar espaços de luta e espaços de autocuidado. E na construção de sua argumentação faz todo sentido essa separação, uma vez que sua crítica se debruça sobre nossa capacidade de avaliar e estabelecer alianças para prosseguirmos vivas e vivos. Para Reagon, a coalizão é um exercício extremamente arriscado no qual você nunca tem total certeza de qual aliança pode lhe custar a vida. Em sua percepção, os espaços de militância não correspondem a espaços de cuidado para os militantes, sendo no máximo espaços para se cuidar daqueles por quem a militância luta. O trabalho de coalizão, como ela diz, é feito nas ruas, em outros termos, de um lado de 'fora' do coletivo que pretende militar. Já o autocuidado seria trabalho para um 'dentro' de casa, do seu abrigo. Todavia, talvez o que ela não pôde considerar em sua fala é que para muitas pessoas LGBTI+ o abrigo está misturado ao espaço de luta. Talvez as concepções de abrigo de muitas de nós (enquanto pessoas LGBTI+) sejam um tanto menos objetivas, uma vez que diversas de nós crescemos em casas que não nos aceitaram, que nos violentaram, ou, não raro, que nos expulsaram, o que estabelece referências muito próprias do que seria um abrigo. Certamente encontramos abrigos noutros lugares: às vezes entre amigas e amigos, às vezes em coletivos online, e muitas vezes nos coletivos militantes onde podemos (des/re)construir nossas percepções de mundo, de nosso direito à vida, de nossas memórias. Mas nada disso exclui as marcas da situação de abrigo em que a maioria de nós viveu boa parte de sua vida e a proximidade simbólica, em nossa sociedade, entre os termos família e abrigo. Inclusive não é incomum pessoas LGBTI+

Vol. 02, N. 01, Jan. - Mar., 2019 - www.revistas.unilab.edu.br/index.php/rebeh 
chamarem de "família" os coletivos (militantes ou não) nos quais se abrigaram após serem abandonadas por seus parentes anteriores. É óbvio que essa imagem não encerra as possibilidades de se compreender e se sentir abrigado. Poderíamos citar, por exemplo, pessoas LGBTI+ que vivem longos anos institucionalizadas (em orfanatos, no sistema carcerário, até mesmo em instituições de saúde mental), que podem ter outras referências sobre abrigo e campo de luta. O ponto é que nem sempre é objetiva a separação entre casa e espaço de coalizão, entre se abrigar e lutar.

São muitas as vivências e experiências que cada grupo, coletivo, indivíduos, ativismos vêm empreendendo como formas desse cuidado. Festas, passeios, congressos LGBTI+, conversas com amigos, espaços coletivos de toda sorte, cines-debate, rodas de conversa, casas de apoio e acolhimento e, inclusive, espaços de militâncias, podem ser oportunidades importantes de promoção de saúde, de cuidarmos umas das outras, de persistirmos. Dentre algumas atividades, como grupos de apoio para pessoas LGBTI+ e para seus familiares, trazemos duas referências significativas. O grupo Mães pela Diversidade, fundado em 2007 por algumas pessoas da cidade de São Paulo, tem hoje diversos grupos que atuam em muitos estados do Brasil, constituídos enquanto uma associação nacional (D'ANGELO, 2018; NOVO, 2017). Outra iniciativa é o Grupo de Pais de Homossexuais (GPH), fundado em 1997 pela psicanalista Edith Modesto, também na cidade de São Paulo (MALUF, 2011). Ambos constituem-se como uma rede de apoio para familiares de pessoas LGBTI+, que apresentam dificuldades pessoais e sociais na relação com suas/seus filhas/os, atuando na organização de encontros, eventos e grupos, presenciais e/ou virtuais, para poderem conversar sobre aceitação, gênero, sexualidade e conscientização sobre LGBTfobia, apoiando as demais famílias para que estas possam dar o apoio necessário a suas/seus filhas/os diante das exclusões sofridas no cotidiano.

Casas de acolhimento e apoio, como a Casa 1 na cidade de São Paulo e a Casa Nem na cidade do Rio de Janeiro, são exemplos de espaços de acolhida de pessoas LGBTI+ que foram expulsas de suas casas e nesses locais encontram não apenas abrigo, mas diversas formas de cuidado e superação das dificuldades encontradas nas relações familiares. Constituídas de ações voltadas para aprimoramento profissional, atividades lúdicas, atividades de estudos e formação, também contam com voluntários que realizam

Vol. 02, N. 01, Jan. - Mar., 2019 - www.revistas.unilab.edu.br/index.php/rebeh 
atividades de atenção e cuidado de suas demandas. Esses espaços aparecem aqui como instituições que lutam por condições sociais menos indignas e fazendo isso promovem espaços de acolhimento importantes para saúde tanto para pessoas LGBTI+ quanto para familiares e amigos delas. Embora não se configurem necessariamente como instituições de saúde, na prática, contribuem para a promoção de saúde por diversas frentes. Esses exemplos não se esgotam em absoluto de todos os espaços-momentos que foram empenhados com esses propósitos, tendo aqui a intenção de mostrar parte dessas iniciativas.

Entretanto, como insistimos em afirmar, as reflexões aqui tentam extrapolar a esfera macropolítica para dar visibilidade a algo do micropolítico, não para separar essas dimensões definitivamente, pois elas só podem ser mais bem compreendidas quando articuladas. Nossa investida é por rastrear novas possibilidades de comunhão, luta e cuidado nos debruçando sobre o micropolítico. E já que você nos acompanhou até aqui, venha conosco circular mais por esse encontro. Quem sabe assim nós possamos apreender alguns rastros sobre como os encontros se articulam na tecitura de nossas redes de cuidado?

\section{(Des)encontros marcados}

Por aqui, entre.

Veja só, pequenos grupos de pessoas conversando numa sala de estar de mais ou menos 10 metros quadrados. Alguns dos grupelhos unidos por marcas comuns. Outros mais diversos em que não se sabe de pronto se o comum ali está de fato em uma identidade ou marca específica. Há ainda membros desgarrados ou que circulam de grupelho em grupelho interagindo momentaneamente. Se olhar com cuidado você

reconhece alguns dos signos na aparência, nos gesticulares, nos vocabulários. São rastros de categorias históricas e modulam consideravelmente nossas interações. Porém, não deixe que seus olhos sejam seduzidos pelo próprio poder, eles têm sido poderosas ferramentas "esmerilhadas à perfeição" com intuito "de distanciar o sujeito cognoscente de todos e de tudo no interesse do poder desmesurado" (HARAWAY, 1995, p. 19). Claro que há singularidades também, gestos inesperados, combinações de vestimentas que não

Vol. 02, N. 01, Jan. - Mar., 2019 - www.revistas.unilab.edu.br/index.php/rebeh 
imaginaríamos, sinais ambíguos, entre outras coisas. Apenas olhos que desconfiam de seu poder de marcar, de escanear, de julgar e sentenciar o outro, somente estes estão (des)preparados o bastante para serem olhados de volta, interpelados pelos acasos e equívocos, e permitirem que o outro se mostre, que o outro viva. Não somos nós apenas que os olhamos aqui de sobrevoo. Somos olhados de volta. Perceba só aquele rapaz flertando com você a distância. Ou a moça que nos olha com certa curiosidade em seus olhos.

A pergunta mais central para o reconhecimento é direta e voltada para o outro: "Quem és tu?". Essa pergunta pressupõe que diante de nós há um outro que não conhecemos e não podemos apreender totalmente, alguém cujas unicidade e não substituibilidade impõem um limite ao modelo de reconhecimento recíproco oferecido no esquema hegeliano e, em termos mais gerais, à possibilidade de conhecer o outro. (BUTLER, 2015, p. 45)

Ninguém está totalmente imune aos encontros entre olhares. Esquive de um olhar, e logo em seguida esbarrará noutro. Eles parecem nos devolver a pergunta: Quem somos nós?

Quando pedimos para conhecer o outro, ou pedimos para que o outro diga, final ou definitivamente, quem é, é importante não esperar nunca uma resposta satisfatória. Quando não buscamos a satisfação e deixamos que a pergunta permaneça aberta e perdure, deixamos o outro viver, pois a vida pode ser entendida exatamente como aquilo que excede qualquer relato que dela possamos dar. Se deixar o outro viver faz parte da definição ética do reconhecimento, tal definição será baseada mais na apreensão dos limites epistêmicos do que no conhecimento. (ibid, p. 61)

De qualquer modo, neste espaço-momento há elementos físicos, simbólicos e discursivos que performam algo de um comum, para citar alguns: o fato de ser um evento em que a maioria é aparentemente LGBTI+; o fato de estarmos fisicamente todos aqui, pois, ainda que a presença não seja necessariamente uma comunhão, nos suscita, no mínimo, solicitações éticas mais imediatas; uma série de convenções e expectativas tácitas ou explícitas que nos fazem reproduzir mais facilmente certos comportamentos em vez de outros; a música vinda dos alto-falantes conectados a um notebook num volume alto o bastante para que precisemos disputar os ouvidos umas das outras falando um pouco mais alto. É uma festa?

Duas moças começam a dançar próximas ao notebook, mas ainda mais próximas uma da outra. Deixamo-las se divertir e seguimos em frente. Aproximamo-nos de um grupo com alguns e algumas universitárias que nos cumprimentam enquanto conversam

Vol. 02, N. 01, Jan. - Mar., 2019 - www.revistas.unilab.edu.br/index.php/rebeh 
sobre a mais recentes decisões do governo. Um dos rapazes ali se exalta ao ler as notícias pelo celular. A maior parte do grupo discute, tenta analisar a situação política atual, faz propostas, compartilha ideias, pontos de vista, receios. Estamos então num debate acadêmico? Quem sabe numa reunião de ativistas?

Circulamos um pouco mais e estacionamos próximo a quatro pessoas que combinavam outro encontro mais tarde numa praça ali perto para comemorem o aniversário de uma delas. Um deles adverte sobre os riscos de ficar na praça até tarde, e começa a contar de uma noite em que foi abordado ali por dois homens que o mandaram soltar a mão do namorado, pois estavam incomodados com as trocas de carinho entre os dois. A única travesti nesta roda de conversa começa a trazer histórias de agressões que recebia em casa, pois seus pais não aceitavam que ela vestisse roupas de mulher. Ria enquanto contava as suas estratégias para driblar o policiamento da família. Ela saía de casa com uma roupa de "boyzinho" como ela classifica. No entanto, antes de ir de fato para o evento, passava na casa de uma amiga para customizar a vestimenta para parecer mais feminina, não raro pegava emprestada roupas e sapatos dessa amiga que por sorte tinha pés grandes como os dela. "Eu era a verdadeira Cinderela da Madrugada!" diz em tom alegre. Gargalha enquanto conta o episódio em que apanhou do primo com quem cruzou numa festa por vê-la trajando um vestido. Isso parece disparar narrativas de outros ali, histórias misturadas a risos e gargalhadas diante das condições precárias que vivem ou viveram.

As agressões, perseguições e ameaças direcionadas a pessoas LGBTI+ parecem marcar essas existências de modo que, quando ocorre dessas pessoas estarem umas com as outras, partilhando experiências semelhantes, podem ter promovido um espaço possível para falar a respeito disso, falar para dar conta disso. Mas elas sorriem, gargalham ao contar sobre suas desventuras. Será que sorriem por que sentem alívio em compartilhar e serem de algum modo compreendidas? Será que gargalham por se sentirem mais acolhidas e seguras ali a ponto de recontarem essas histórias para si e para os outros, como se não fossem tóxicas, paralisantes ou amedrontadoras? Ali, aqueles corpos fazem suas experiências circularem, circulam pelos armários, abrigos, ruas e madrugadas uns dos outros, ressignificam as violências e medos que sentiram e sentem 
para que juntos tornem suas vidas mais vivíveis, porque não retornam sozinhas a essas memórias. E nesse retorno (re)elaboram a própria história.

De início pode parecer que rir seja apenas um jeito de negar os perigos e medos. Mas e se rir também puder ser um jeito de enfrentar perigos e medos, em vez de uma fuga deles; um jeito de rasurar nossas experiências, de revisitar nossos traumas, mas agora na companhia de outras pessoas que viveram situações semelhantes, ou que compartilham zonas de precariedade maximizada e se acolhem mutuamente para resistirem juntas por condições menos indignas; e se rir juntas permitiu nesta cena (re)elaborar as memórias e viabilizou que agora cada corpo que cruzar aquela porta afora, saia menos sozinho do que quando entrou por ali anteriormente.

[...] aliança não é apenas uma forma social futura; algumas vezes ela está latente ou, outras vezes é efetivamente a estrutura de nossa própria formação subjetiva, como quando a aliança acontece dentro de um único sujeito, quando é possível dizer: "Eu mesmo sou uma aliança, ou eu me alinho comigo mesmo e às minhas várias vicissitudes culturais". O que significa apenas que o "eu" em questão se recusa a tornar secundário um estatuto de minoria ou lugar de condição precária vivido em favor de qualquer outro. (BUTLER, 2018, p. 77)

Cada 'eu' leva um 'nós' consigo. E os encontros são momentos de tencionamento e confecção desse "nós". Os encontros são uma oportunidade de ampliar e reafirmar essa coletividade. Perceba como este espaço-momento se constrói, em diversos níveis e tons, como uma rede de cuidado e de partilha dos sofrimentos, de traçados coletivos de estratégias, de constituição de alianças, constituindo inclusive nuances e dimensões diferentes para este espaço-momento. Talvez seja nos termos do cuidado mútuo que se possa haver a forja de um comum efetivamente aberto para acolher a multiplicidade de vidas em risco, para tecer alianças inclusive com outros grupos minoritários expostos a maximização da precariedade.

\section{Considerações finais}

Por tudo dito até aqui, defendemos a importância de compreender os encontros como espaços possíveis para a promoção e formas de cuidado de saúde mental de pessoas LGBTI+. Objetivamos pensá-la a partir de uma reflexão crítica que buscou levantar a problemática de condições em que um cuidado mútuo pode ser o denominador comum constituído em/por meio às narrativas produzidas e compartilhadas no(s) 
coletivo(s), colaborando para a tecitura de redes de proteção e promoção de saúde mental, na medida em que contribuem com formas de enfrentamentos da realidade social, e produzem meios locais de minimizar suas condições precárias desiguais. Mais do que pensarmos em políticas e serviços, pensamos em destacar como a força dessas narrativas produzidas nos encontros podem proporcionar condições de mútua proteção, cuidado, saúde e bem-estar. Muitos desses encontros constituem-se como o lugar de abrigo, em que alianças se tornam mais do que lutas políticas, tornam-se o lugar de morada e de possibilidade de existências singulares, em que outros modos de existência podem ser possíveis e desejos dissidentes podem encontrar desejos comuns.

Consideramos que estar em coletivo é mais do que estar junto, pois depende de um envolver-se, uma vez que, precisamos olhar para o encontro com alguma criticidade, de si e do grupo, como uma maneira de nos responsabilizarmos pelo que ele pode representar. Há um exercício do encontrar para que os diversos espaços-momentos façam sentido e viabilizem uma possível (re)elaboração de sofrimentos e violências cotidianas. Tanto Reagon (2000), quanto Haraway (2000) e Butler (2016a, 2016b, 2018) são unanimes ao reconhecer o valor de estarmos juntas e conectadas para garantir a persistência das vidas, sobretudo, para as populações consideradas minoritárias. Neste quadro, a questão da saúde nos parece inalienável dessa perseverança.

Refletindo a partir de Spinoza (2009) que "cada coisa esforça-se [...] por perseverar em seu ser" (SPINOZA, 2009, p. 105) se tem algo que sabemos é perseverar. Para muitas e muitos de nós, estarmos juntas, constituirmos atividades em coletivo, agregarmos pessoas que carecem de acolhida, fortalecermos nossa luta, lutarmos pela nossa vivência é perseverar diante das vicissitudes impostas pelos poderes hegemônicos excludentes e ameaçadores. É no coletivo que nossas narrativas podem perseverar e serem levadas adiante por condições mais dignas, menos insalubres e mais igualitárias.

Diante de uma realidade política nacional que nos mostra regressiva e tenebrosa, nossa luta é nossa resistência, nossas alianças são nossa persistência, e diante da precariedade, nosso cuidado mútuo também é uma forma de lutar. Como Butler (2018), afirmamos que, para que a luta por condições mais vivíveis para as pessoas LGBTI+ seja uma luta por justiça social, precisamos também estabelecer encontros e práticas de cuidado mútuo com outras populações expostas a injustiças sociais, que também se 
encontram em situações vulnerabilizadas e que estão marcadas para além das identidades dissidentes de gênero e sexualidade. Isso nos parece fundamental se queremos realmente ampliar a rede de cuidado extrapolando as estruturas do poder público.

Vemos nos encontros oportunidades de tensionamento do "nós" que, através de suas histórias de vida em composição individual e coletiva, faz circular narrativas diversas, de modo a proporcionar elaborações das memórias e a construção de um comum que comporta não apenas a multiplicidade dessas vidas e existências, como constitui-se em formas de cuidado mútuo daqueles que se encontram e compartilham zonas de precariedade maximizada em direção a terem reconhecimento devido como vidas vivíveis e dignas de respeito.

Quando trazemos a discussão da promoção e cuidados de saúde mental da população LGBTI+ ao nível das alianças e narrativas produzidas nos encontros locais, procuramos investir em uma reflexão micropolítica, que compreende um reinvestimento do desejo em outros territórios que possam escapar às normas de sexualidade e gênero que nos aprisionam e nos adoecem. Do mesmo modo que esse reinvestimento em outros territórios possibilita reconsiderarmos nossas lutas e olharmos novamente para nossa história para podermos ampliar nossas redes e práticas, constituindo outras formas de cuidados e acolhimentos de nossas saúdes mentais. Da terra arrasada podemos fazê-la terra movediça da cobiça do capitalismo hegemônico e mobilizar nossos desejos para um caminho de multiplicidade e ampliação do comum.

\section{Referências:}

AMÉLIA, Silvia. O que você precisa saber sobre o "kit gay". Diário do Centro do Mundo (DCM). Online, 10 out. 2018. Disponível em:

https://www.diariodocentrodomundo.com.br/o-que-voce-precisa-saber-sobre-o-kit-gaypor-silvia-amelia/. Acesso em: 12 jan 2019.

BENJAMIN, Walter. Obras Escolhidas: Magia e técnica, ciência e arte. $3^{\text {a}}$ Ed. São Paulo: Ed Brasiliense, 1987.

BUTLER, Judith. Corpos em aliança e a política das ruas: Notas para uma teoria performativa de assembléia. $1^{\mathrm{a}}$ ed. Rio de Janeiro: Civilização Brazileira, 2018. 
BUTLER, Judith. Corpos que ainda importam. In: COLLING, Leandro. Dissidências sexuais e de gênero. Salvador: EDUFFBA, 2016a. p. 19-42

BUTLER, Judith. Quadros de Guerra: quando a vida é passível de luto? 2aed. Rio de Janeiro: Civilização Brasileira, 2016b.

BUTLER, Judith. Relatar a si mesmo: crítica da violência ética. Belo Horizonte: Ed Autentica, 2015.

D’ÂNGELO, Helô. Há 10 anos, grupo Mães pela Diversidade conscientiza mães e pais sobre LGBTfobia. Cult. Editora Bregantini, 11 mai. 2018. Disponível em: https://revistacult.uol.com.br/home/maes-pela-diversidade-lgbtfobia/. Acesso em: 07 jun. 2019

DELEUZE, Gilles; PARNET, Claire. Diálogos. São Paulo: Escuta, 1998.

DIÁRIO DE PERNAMBUCO. Pernambuco: Grupo R2, 2 jan. 2019. Disponível em: http://www.diariodepernambuco.com.br/app/noticia/politica/2019/01/02/interna_politica ,772675/mp-assinada-por-bolsonaro-retira-populacao-lgbt-das-diretrizes-dosdir.shtml?fbclid=IwAR0gyR85ueqld31Hi4OzGCDZ4Zycm9wJJP_rtc12jGuHus4byPRf wgZiKBg. Acesso em: 10 jan 2019.

FERREIRA, Marcelo Santana. Enunciações de si em estudos sobre as sexualidades: proposições metodológicas. In: FERREIRA, Marcelo S.; MORAES, Márcia (org.). In: Políticas de pesquisa em psicologia social. Rio de Janeiro: Nova Aliança Editora e Papéis, 2016. p. 93- 116.

FOUCALT, Michel. História da Sexualidade 1: A vontade de saber. Tradução de Maria Thereza da Costa Albuquerque e J. A. Guilhon Albuquerque. 2a ed. São Paulo: Paz e Terra, 2015.

GUATTARI, Felix; ROLNIK, Suely. Micropolítica. Cartografias do Desejo. 12a ed. Petrópolis: Editora Vozes. 2013.

HARAWAY, Donna. O Manifesto Ciborgue. In: Antropologia ciborgue: as vertigens do pós-humano. $2^{a}$ ed. Belo Horizonte: Autêntica, 2009. p. 33-118.

HARAWAY, Donna. Saberes localizados: a questão da ciência para o feminismo e o privilégio da perspectiva parcial. In: Cadernos Pagu, v.5. p. 7-41. Campinas: Ed. Unicamp, $1995 . \quad$ Disponível em: https://periodicos.sbu.unicamp.br/ojs/index.php/cadpagu/article/view/1773. Acesso em: 07 de jun. 2019

MACRAE, Edward. A construção da igualdade: identidade sexual e política no Brasil da abertura. Campinas: Editora da UNICAMP, 1990.

MALUF, Vladimir. Para ser gay, tem de ser muito macho. Online. Universia. 25 jun. 2011. Disponível em: https://universa.uol.com.br/noticias/redacao/2011/06/25/para-sergay-tem-de-ser-muito-macho-diz-fundadora-do-grupo-de-pais-de-

homossexuais.htm?cmpid=copiaecola. Acesso em: 05 jun 2019.

MARTINHÃO, Viviane Suzano. Análise do dispositivo identitário no processo de subjetivação do Movimento LGBT na busca por direitos e cidadania. 2017. $176 \mathrm{f}$. Dissertação (Mestrado em Psicologia Social). Programa de Pós Graduação em

Vol. 02, N. 01, Jan. - Mar., 2019 - www.revistas.unilab.edu.br/index.php/rebeh 
Psicologia Social - Instituto de Psicologia, Universidade do Estado do Rio de Janeiro, Rio de Janeiro, 2017.

NOVO, Arthur Leonardo Costa. "Mães pela diversidade": as políticas da parentalidade em um grupo ativista de mães e pais de pessoas LGBT. Seminário Internacional Fazendo Gênero 11 \& 13thWomen's Worlds Congress (Anais Eletrônicos), Florianópolis, 2017. Disponível em: http://www.en.wwc2017.eventos.dype.com.br/resources/anais/1499466896_ARQUIVO _artigoFGMM11_final.pdf. Acesso em: 05 jun 2019

PERES, Milena Cristina Carneiro; SOARES, Suane Felippe; DIAS, Maria Clara. Dossiê sobre lesbocídio no Brasil: de 2014 até 2017. Rio de Janeiro: Livros Ilimitados, 2018. Disponível em: https://dossies.agenciapatriciagalvao.org.br/fontes-e-pesquisas/wpcontent/uploads/sites/3/2018/04/Dossi\%C3\%AA-sobre-lesboc\%C3\%Addio-noBrasil.pdf. Acesso em: 07 de jun. 2019

REAGON, Bernice Johnson. Coalition politics: turning the century. In: SMITH, Barbara Home girls: A Black feminist antology. Kitchen Table: Woman of color press, 1983. Reprinted by: Rutgers University Press, New Jersey, 2000

REIS, Maria. Por que é melhor usar o termo LGBTfobia no lugar de homofobia? El País. Brasil, 18 de mai. 2018

SEDGWICK, Eve Kosofsky. A epistemologia do armário. Cadernos Pagu. Campinas, n. 28, p. 19-54, junho de 2007. Disponível em: http://www.scielo.br/scielo.php?pid=S0104$83332007000100003 \&$ script $=$ sci_abstract\&tlng=pt. Acesso em: 07 de jun. 2019 http://dx.doi.org/10.1590/S0104-83332007000100003.

SOARES, Wellington. Conheça o "kit gay" vetado pelo governo federal em 2011. Nova Escola. Fundação Leman, 1 fev. 2015. Disponível em: https://novaescola.org.br/conteudo/84/conheca-o-kit-gay-vetado-pelo-governo-federalem-2011. Acesso em: 07 jun. 2019.

SPINOZA, Benedictus de. Ética. Tradução de Tomaz Tadeu. Belo Horizonte: Autêntica Editora, 2009.

TEIXEIRA-FILHO, Fernando Silva; RONDINI, Carina. Ideações e tentativas de suicídio em adolescentes com práticas sexuais hetero e homoeróticas. Saude soc. [online]. 2012, vol.21,n.3, pp.651-667. Disponível em: http://www.scielo.br/scielo.php?script=sci_arttext\&pid=S010412902012000300011\&lng=en\&nrm=iso. Ácesso em: 07 de jun. 2019 ISSN 0104-1290. http://dx.doi.org/10.1590/S0104-12902012000300011.

\section{ENCUENTROS MARCADOS:}


Resumen: En este artículo presentamos el tema de la salud mental de la población LGBTI + más allá de las formalidades estatales. Abordamos las narrativas de historias de vida establecidas en los encuentros entre esas personas, viabilizadas por colectivos LGBTI + desde grupos de activistas, de amigos, o incluso situaciones sociales como fiestas, encuentros inesperados. Nos preguntamos cómo estos espacios-momentos pueden viabilizar la circulación de las narrativas LGBTI +, la elaboración de memorias, y la propia constitución subjetiva de los sujetos a través del compartir experiencias singulares y que, al mismo tiempo, cargan o desempeñan rastros de común. Extendemos la reflexión para como esto puede contribuir en la tejitura de una red de cuidado más amplia, que activamente promueva estrategias, alianzas y condiciones más vivibles, constituyéndose como formas de acogida, atención, cuidado y protección que promueven y fortalecen la salud mental. Reconocemos la importancia de seguir en la lucha por la garantía de políticas, pero apostamos que no basta con buscar la garantía de salud a través del poder público, pensar otras formas de proporcionar espacios de encuentros que creen o ayuden a crear las condiciones de (sobre)vivencia menos vulnerables por las opresiones cotidianas, así como estrategias de enfrentamiento de las realidades opresivas. Ante la actual realidad política necesitamos (re)considerar nuestras luchas y prácticas, encaminando medios de hacer que nuestras vidas sean más vivibles, comprendiendo el cuidado mutuo para la apertura a las multiplicidades de las vidas y narrativas que perseveran. Atentamos para la construcción de redes interseccionales de alianzas, entendiendo que diversos marcadores de diferencia son convocados en esa lucha por el derecho a la libertad de ser plurales.

Palabras-Clave: Salud Mental LGBTI+; Memoria LGBTI +; Narrativas; Políticas de Alianza; Redes de cuidado.

Recebido em: 16/01/2019

Aceito em: 09/02/2019 